\title{
Modeling SOA formation from the oxidation of intermediate volatility $\boldsymbol{n}$-alkanes
}

\author{
B. Aumont ${ }^{1}$, R. Valorso ${ }^{1}$, C. Mouchel-Vallon ${ }^{1}$, M. Camredon ${ }^{1}$, J. Lee-Taylor ${ }^{2}$, and S. Madronich ${ }^{2}$ \\ ${ }^{1}$ LISA, CNRS/INSU UMR7583, Université Paris Est Créteil et Université Paris Diderot, Institut Pierre Simon Laplace, \\ 94010 Créteil, France \\ ${ }^{2}$ NCAR, National Center for Atmospheric Research, Boulder, CO, USA
}

Correspondence to: B. Aumont (bernard.aumont@lisa.u-pec.fr)

Received: 24 May 2012 - Published in Atmos. Chem. Phys. Discuss.: 7 June 2012

Revised: 11 August 2012 - Accepted: 13 August 2012 - Published: 21 August 2012

\begin{abstract}
The chemical mechanism leading to SOA formation and ageing is expected to be a multigenerational process, i.e. a successive formation of organic compounds with higher oxidation degree and lower vapor pressure. This process is here investigated with the explicit oxidation model GECKOA (Generator of Explicit Chemistry and Kinetics of Organics in the Atmosphere). Gas phase oxidation schemes are generated for the $\mathrm{C}_{8}-\mathrm{C}_{24}$ series of $n$-alkanes. Simulations are conducted to explore the time evolution of organic compounds and the behavior of secondary organic aerosol (SOA) formation for various preexisting organic aerosol concentration $\left(C_{\mathrm{OA}}\right)$. As expected, simulation results show that (i) SOA yield increases with the carbon chain length of the parent hydrocarbon, (ii) SOA yield decreases with decreasing $C_{\mathrm{OA}}$, (iii) SOA production rates increase with increasing $C_{\mathrm{OA}}$ and (iv) the number of oxidation steps (i.e. generations) needed to describe SOA formation and evolution grows when $C_{\mathrm{OA}}$ decreases. The simulated oxidative trajectories are examined in a two dimensional space defined by the mean carbon oxidation state and the volatility. Most SOA contributors are not oxidized enough to be categorized as highly oxygenated organic aerosols (OOA) but reduced enough to be categorized as hydrocarbon like organic aerosols (HOA), suggesting that OOA may underestimate SOA. Results show that the model is unable to produce highly oxygenated aerosols (OOA) with large yields. The limitations of the model are discussed.
\end{abstract}

\section{Introduction}

Fossil fuel and biomass combustion leads to the emission of long carbon chain hydrocarbons $\left(\mathrm{C}_{>10}\right)$ in the atmosphere. A large fraction of these Intermediate Volatility Organic Compounds (IVOC) is expected to be first emitted in the condensed phase and rapidly volatilized by atmospheric dilution (Robinson et al., 2007). IVOC are expected to be major precursors of secondary organic aerosols (SOA) (Robinson et al., 2007; Grieshop et al., 2009). The SOA formation potential was recently examined in laboratory studies for few IVOC precursors, mostly alkanes (Lim and Ziemann, 2009; Presto et al., 2010), alkenes (Matsunaga et al., 2009), aromatics (Chan et al., 2009) and oxygenated IVOC (ChaconMadrid and Donahue, 2011). These experimental studies confirmed the high SOA formation potential for such precursors. Furthermore, recent numerical simulations have shown that IVOC are likely a substantial source of SOA in the plume of megacities (e.g. Dzepina et al., 2011; Tsimpidi et al., 2010; Hodzic et al., 2010; Li et al., 2011; Lee-Taylor et al., 2011) and at continental scales (Jathar et al., 2011).

The chemical mechanism leading to SOA formation and ageing is expected to be a multigenerational process, i.e. a successive formation of organic compounds with higher oxidation degree and lower vapor pressure (e.g. Camredon et al., 2007; Kroll and Seinfeld, 2008). Parameterizations were recently developed to describe this process in a simplified way. For example, multigenerational oxidation is represented in the volatility basis set (VBS) approach by a decrease in the volatility and an increase of the mass after each oxidation step (e.g. Robinson et al., 2007; Grieshop et al., 
2009; Donahue et al., 2006, 2011, 2012). These parameterizations are developed with an empirical approach, based on laboratory observations. However, major uncertainties remain concerning these multigenerational processes and, as a result, parameterizations implemented in current models to account for SOA formation and ageing from IVOC precursors are weakly constrained. The development of such parameterizations suffers from a lack of information concerning the chemical mechanism controlling SOA formation and evolution in the atmosphere.

The aim of this study is to explore SOA formation from IVOC precursors using an explicit modeling approach. Alkanes are major contributors to anthropogenic emissions (Calvert et al., 2008; Lim and Ziemann, 2005) and this chemical family was recently used as a substitute for IVOC emissions (Lee-Taylor et al., 2011). Here, we develop explicit oxidation schemes for the $n$-alkane series $\left(\mathrm{C}_{8}-\mathrm{C}_{24}\right)$, using the self-generating mechanism GECKO-A (Aumont et al., 2005; Camredon et al., 2007). These schemes are used to examine the contribution of the multigenerational process to the time evolution of the gas and aerosol phases. The modeling tools and simulations are presented in Sect. 2 and results are discussed in Sect. 3.

\section{Model description}

\subsection{The GECKO-A mechanisms}

The development of explicit oxidation schemes for IVOC precursors involves millions of reactions and secondary organic species, far exceeding the size of chemical schemes that can be written manually (Aumont et al., 2005; Goldstein and Galbally, 2007; Kroll et al., 2011). Here, gas-phase oxidation schemes were generated automatically using the Generator for Explicit Chemistry and Kinetics of Organics in the Atmosphere (GECKO-A) (Aumont et al., 2005; Camredon et al., 2007; Valorso et al., 2011). This tool can be viewed as an expert system that mimics the steps by which chemists might develop chemical schemes, i.e. writing the list of the reactions involved in the oxidation of a given species and their associated rate constants.

GECKO-A generates chemical schemes according to a prescribed protocol assigning reaction pathways and kinetics data on the basis of experimental data and StructureActivity Relationships (SAR). The protocol is the set of rules that lays out the choice of reaction pathways and estimates the rate coefficients needed in the mechanism based on the species' molecular structure. The protocol currently implemented in GECKO-A is described by Aumont et al. (2005). The chemical fate of alkoxy radicals produced during oxidation plays a crucial role in the context of the present study. These radicals either fragment (i.e. C-C bond breaking), functionalize the carbon skeleton by $\mathrm{O}_{2}$ reaction, or isomerize via an H-shift (e.g. Atkinson and Arey, 2003). The fragmentation route progressively breaks the carbon skeleton and ultimately leads to $\mathrm{CO}_{2}$ production after several successive oxidation steps. The functionalization route progressively adds functional groups to the carbon backbone and leads eventually to the formation of species with low vapor pressure that may condense onto preexisting aerosol. The GECKO-A protocol was therefore updated to include the recent SAR of Atkinson (2007) for alkoxy radical chemistry. In addition, the SAR of Kwok and Atkinson (1995) implemented in GECKO-A for the reaction of aliphatic compounds with $\mathrm{OH}$ radicals was updated to include the recommendation of Bethel et al. (2001) about the reactive sites in the vicinity of alcoholic moiety. To our knowledge, the schemes generated by GECKO-A are the sole gas phase mechanisms currently available to describe in a detailed way the oxidation of IVOC in the atmosphere.

The saturation vapor pressure $P^{\text {vap }}$ is required to describe phase partitioning (Pankow, 1994) for the organic species involved in the mechanism. Here, $P^{\text {vap }}$ was estimated for every non-radical species using the Nannoonal et al. (2008) method, coupled with the Nannoonal et al. (2004) SAR to estimate the required boiling points. Barley and McFiggans (2010) recently identified this method as one of the most reliable SAR to estimate $P^{\mathrm{vap}}$ in the context of SOA production. Furthermore, this method was found by Valorso et al. (2011) to provide the best agreement of the simulated SOA yields with smog chamber observations. Group contribution values not provided by Nannoonal et al. $(2004,2008)$ were taken from Compernolle et al. (2010), as described in Valorso et al. (2011).

Assuming that the gas/particle partitioning is controlled by an absorption process (Pankow, 1994), and that the aerosol is a well mixed homogeneous phase, thermodynamic equilibrium is described by:

$P_{i}=\gamma_{i} x_{i} P_{i}^{\text {vap }}$

where $x_{i}$ is the mole fraction of species $i$ in the aerosol phase, $P_{i}^{\text {vap }}$ its saturation vapor pressure, $\gamma_{i}$ its activity coefficient and $P_{i}$ its equilibrium partial pressure. Phase partitioning was implemented in the model as described by Camredon et al. (2007). Briefly, thermodynamic equilibrium is enforced at each time step, assuming ideality for the aerosol phase $\left(\gamma_{i}=1\right)$. Equation (1) is solved for the set of organic species using a simple iterative method (Pankow, 1994). For the gas phase oxidation, time integration is solved using the 2-step solver (Verwer and Vanloon, 1994; Verwer et al., 1996). In this model configuration, no reactions occur in the condensed phase. 


\subsection{Simulation conditions}

At thermodynamic equilibrium, the fraction $\xi_{i}$ of a species $i$ in the aerosol phase is given by (e.g. Donahue et al., 2006):

$$
\begin{aligned}
\xi_{i}^{\text {aer }} & =\frac{N_{i, \text { aer }}}{N_{i, \text { aer }}+N_{i, \text { gas }}} \\
& =\left(1+\frac{\bar{M}_{\mathrm{OA}} \gamma_{i} P_{i}^{\text {vap }}}{C_{\mathrm{OA}} R T} \times 10^{6}\right)^{-1}=\left(1+\frac{C_{i}^{*}}{C_{\mathrm{OA}}}\right)^{-1}
\end{aligned}
$$

where $N_{i, j}$ is the number concentration in phase $j$ (molecule of species $i$ per $\mathrm{cm}^{3}$ of air), $R$ is the ideal gas constant (atm m${ }^{3} \mathrm{~K}^{-1} \mathrm{~mol}^{-1}$ ), $T$ the temperature (K), $C_{\mathrm{OA}}$ the aerosol mass concentration $\left(\mu \mathrm{g} \mathrm{m}^{-3}\right.$ of air), $\bar{M}_{\mathrm{OA}}$ is the mean organic molar mass in the aerosol $\left(\mathrm{g} \mathrm{mol}^{-1}\right)$ and $C_{i}^{*}$ is an effective saturation mass concentration $\left(\mu \mathrm{g} \mathrm{m}^{-3}\right.$ of air). Beyond the pure compound properties ( $\left.P^{\mathrm{vap}}\right), C_{\mathrm{OA}}$ appears as a key parameter driving the phase distribution of a given organic species. Simulations were conducted for fixed aerosol mass concentrations, with values set in the $0.1-1000 \mu \mathrm{g} \mathrm{m}^{-3}$ range. This range encompasses typical atmospheric levels and most experiments performed in smog chambers. For $\bar{M}_{\mathrm{OA}}$, a reasonable range might be $100-300 \mathrm{~g} \mathrm{~mol}^{-1}$ (Pankow, 1994). Here, a value of $250 \mathrm{~g} \mathrm{~mol}^{-1}$ was used.

The number of species included in the oxidation scheme generated by GECKO-A grows exponentially with the number of carbon atom of the precursor (Aumont et al., 2005). For a $\mathrm{C}_{8}$ parent compound, the explicit mechanism contains about $10^{6}$ species, close to computational limits for box modeling. Target species in this study are the $\mathrm{C}_{8}-\mathrm{C}_{24} n$-alkanes and significant reductions are required to bring the schemes down to a manageable size. Equation (2) shows that species having a vapor pressure below $10^{-13} \mathrm{~atm}$ will be almost exclusively in the aerosol phase, even for a low aerosol content $\left(\xi_{i}>0.99\right.$ for $\left.C_{\mathrm{OA}}>0.1 \mu \mathrm{g} \mathrm{m}^{-3}\right)$. Such species can be classified as non-volatile under atmospheric conditions and their gas phase oxidation can be considered as insignificant. These species are therefore treated as end products during mechanism generation. With this approximation, the computational limits are reached for $\mathrm{C}_{12}$ hydrocarbons (Aumont et al., 2008). To further decrease the number of species, a lumping protocol has been implemented in GECKO-A (Aumont et al., 2008; Valorso et al., 2011; Lee-Taylor et al., 2011). This lumping protocol is not used in the present study so that the oxidation process described is fully explicit. Instead, we restricted the mechanism to high $\mathrm{NO}_{\mathrm{x}}$ conditions, ignoring the cross reactions between peroxy radicals. Formation of hydroperoxides from the $\mathrm{RO}_{2}+\mathrm{HO}_{2}$ reactions is thus not considered in this study. This is a severe approximation, especially to examine the chemical evolution on timescales exceeding one day for which keeping high $\mathrm{NO}_{\mathrm{x}}$ is hardly representative of atmospheric conditions. Simulations performed here are clearly exploratory and intended to examine some, though not all, aspects of SOA formation during the multigenerational oxidation of long carbon chain of aliphatic species. Finally, additional reductions of the chemical scheme were still required for long chain alkanes $\left(\mathrm{C}_{>16}\right)$ to remain within the computational limits. For these species, the number of generation in the oxidation mechanism of the precursor was limited to 6 . For hexadecane, simulations showed that increasing the number of generations does not lead to significant changes in the composition and evolution of the gas and aerosol phases. Table 1 lists the number of species finally included in the mechanisms for the various precursors.

Oxidation of the IVOC precursors leads to SOA formation. This process may obviously contribute to a significant increase in the prescribed aerosol concentration $C_{\mathrm{OA}}$. In this study, the initial concentration $C_{0}$ of the precursor is selected to be negligible compared to $C_{\mathrm{OA}}$. The initial mixing ratio was set to $10 \mathrm{ppt}$ carbon (about $6.5 \times 10^{-3} \mu \mathrm{g} \mathrm{m}^{-3}$ ). For such conditions $\left(C_{0} \ll C_{\mathrm{OA}}\right)$, the simulated aerosol concentration is proportional to $C_{0}$ or, in other words, the time-dependent aerosol yield is independent of $C_{0}$.

The simulations are performed with constant physical conditions. Temperature is fixed at $298 \mathrm{~K}$. Photolysis frequencies are computed for mid-latitude and for a solar zenith angle of $30^{\circ}$ using the TUV model (Madronich and Flocke, 1997). $\mathrm{NO}_{\mathrm{x}}$ concentration is held constant at a value of $1 \mathrm{ppb}$. Finally, an $\mathrm{OH}$ source of $2 \times 10^{7}$ radicals $\mathrm{cm}^{-3} \mathrm{~s}^{-1}$ was included to initiate the oxidation of the organic species. For these conditions, organic oxidation is almost exclusively driven by $\mathrm{OH}$.

\section{Results}

\subsection{Carbon budget}

Figure 1 shows the distribution of secondary organic carbon in the aerosol and gas phase as well as in the form of the final oxidation products $\mathrm{CO}$ or $\mathrm{CO}_{2}$. In Fig. 1, the simulated time is scaled to typical atmospheric conditions. We define here the photochemical age $\tau$ as:

$$
\tau=\frac{1}{[\mathrm{OH}]_{\mathrm{atm}}} \int_{0}^{t}[\mathrm{OH}]_{\mathrm{sim}} \mathrm{d} t
$$

where $[\mathrm{OH}]_{\mathrm{atm}}$ is the typical $\mathrm{OH}$ concentration in the atmosphere (here taken as $10^{6}$ molecule $\mathrm{cm}^{-3}$ ), and $[\mathrm{OH}]_{\mathrm{sim}}$ is the simulated $\mathrm{OH}$ concentration. Figure 1 shows that aerosol yields grow with $C_{\mathrm{OA}}$ and with the chain length of the parent compound. The opposite trend is found for $\mathrm{CO}$ and $\mathrm{CO}_{2}$ production. After 10 days of atmospheric oxidation, the carbon initially present as octane mainly ends up in the form of $\mathrm{CO}$ and $\mathrm{CO}_{2}$ (typically $70 \%$ ), the remaining fraction being mostly gas phase organic carbon. The aerosol yield for octane becomes significant only for conditions representative of some smog chamber experiments (about $15 \%$ on a carbon basis when $\left.C_{\mathrm{OA}}=10^{3} \mu \mathrm{g} \mathrm{m}^{-3}\right)$. For tetracosane $\left(\mathrm{C}_{24}\right.$ 
Table 1. Number of species considered in the gas phase oxidation mechanism generated with GECKO-A and number of non-radical species for which gas/aerosol equilibrium is accounted.

\begin{tabular}{lll}
\hline Parent alkane & $\begin{array}{l}\text { Number of species } \\
\text { in the mechanism }\end{array}$ & $\begin{array}{l}\text { Number of phase } \\
\text { equilibria }\end{array}$ \\
\hline Octane & $6.4 \times 10^{4}$ & $1.6 \times 10^{4}$ \\
Decane & $2.5 \times 10^{5}$ & $6.5 \times 10^{4}$ \\
Dodecane & $6.7 \times 10^{5}$ & $1.8 \times 10^{5}$ \\
Tetradecane & $1.4 \times 10^{6}$ & $4.1 \times 10^{5}$ \\
Hexadecane* & $8.6 \times 10^{5}$ & $2.9 \times 10^{5}$ \\
Octadecane* & $1.2 \times 10^{6}$ & $4.2 \times 10^{5}$ \\
Eicosane* $^{6}$ & $1.4 \times 10^{6}$ & $5.1 \times 10^{5}$ \\
Docosane $^{*}$ & $1.5 \times 10^{6}$ & $5.3 \times 10^{5}$ \\
Tetracosane $^{*}$ & $1.4 \times 10^{6}$ & $5.3 \times 10^{5}$ \\
\hline
\end{tabular}

${ }^{*}$ Chemical mechanism generated up to the 6th generation only.

$n$-alkane), the fraction of the carbon that is ultimately oxidized to $\mathrm{CO}$ or $\mathrm{CO}_{2}$ is minor for $C_{\mathrm{OA}}=0.1 \mu \mathrm{g} \mathrm{m}^{-3}$ (about $10 \%)$ and becomes negligible for higher aerosol load. On a carbon basis, the aerosol yield is close to 1 (see Fig. 1). However, for $C_{\mathrm{OA}}=10^{3} \mathrm{\mu g} \mathrm{m}^{-3}$, the oxidation process becomes very slow owing to a strong partitioning of tetracosane to the particle phase (represented as inert in this model configuration). Hexadecane shows an intermediate behavior. For atmospheric conditions (i.e. $C_{\mathrm{OA}}$ in the $0.1-10 \mu \mathrm{g} \mathrm{m}^{-3}$ range), the carbon distribution is initially dominated by the production of gas-phase intermediates, and subsequently by particulate or oxidized carbon. After 10 days of oxidation, particulate organic carbon is the major fraction $(60-75 \%)$, the remaining carbon being mostly $\mathrm{CO}+\mathrm{CO}_{2}(20-35 \%)$.

The carbon evolution shown in Fig. 1 is a multigenerational oxidative process. Oxidation leads to progressive functionalization of the carbon skeleton and produces successive generations of compounds with lower volatility. Aerosol formation occurs when species with low enough volatility are produced. This volatility threshold is linked to the aerosol load $C_{\mathrm{OA}}$ (Eq. 2). The functionalization mechanism competes with the fragmentation of the carbon backbone, the latter leading to the successive formation of organic intermediates with higher volatility and ultimately to $\mathrm{CO}_{2}$. Note that the fragmentation probability increases with the number of organic moieties born by the carbon skeleton (e.g. Atkinson, 2007; Calvert et al., 2011; Chacon-Madrid and Donahue, 2011). For octane oxidation, fragmentation of the carbon backbone takes place before sufficient functionalization to allow SOA formation (see also Sect. 3.6) and thus progressively leads to the formation of $\mathrm{CO}$ and $\mathrm{CO}_{2}$ as shown in Fig. 1. For hexadecane, functionalization leads in a few generations to the formation of non-volatile compounds that partition to the aerosol phase. Fragmentation is however still significant, especially for low $C_{\mathrm{OA}}$ (see Fig. 1). Finally for tetracosane, fragmentation appears as a minor mechanism, since

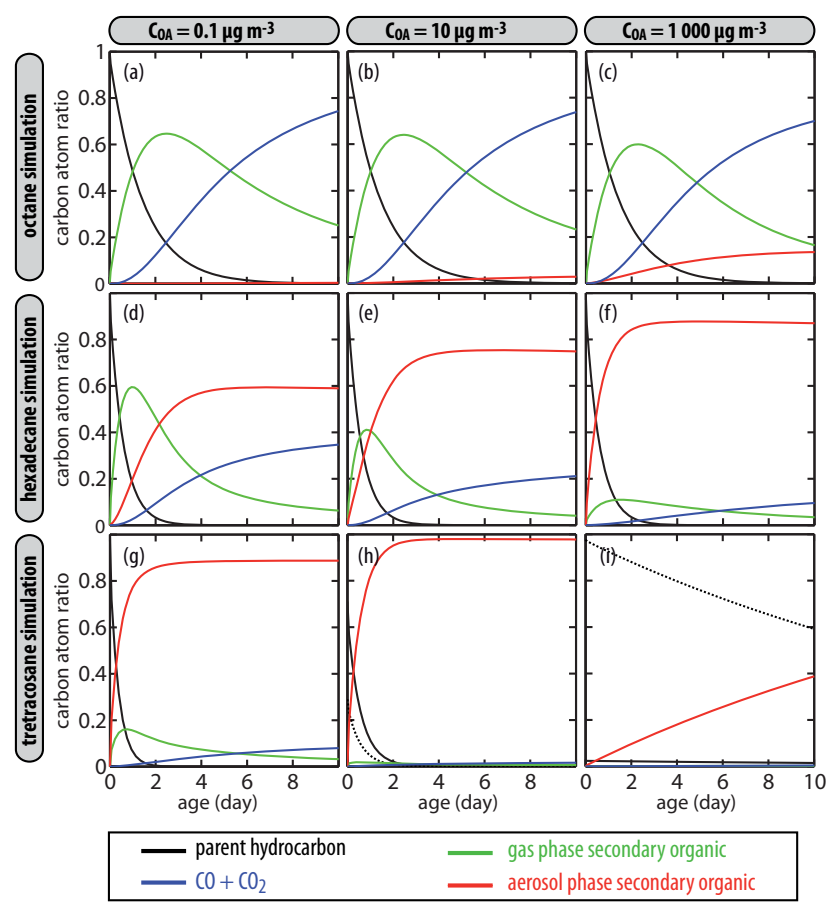

Fig. 1. Carbon budget during the oxidation of octane (top line) hexadecane (middle line) and tetracosane (bottom line) for $C_{\mathrm{OA}}$ con-

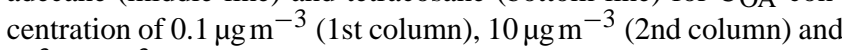
$10^{3} \mu \mathrm{g} \mathrm{m}^{-3}$ (3rd column). Continuous and dotted black lines in panels $\mathrm{h}$ and $\mathrm{i}$ denote the parent compound in the gas phase and particulate phase, respectively.

organic species produced by the first oxidation steps are of low enough volatility to partition to the particles (where further oxidation in not considered in this version of the model). This multigenerational oxidation mechanism is examined in detail in the section below.

\subsection{The multigenerational oxidation step by step}

The GECKO-A tool generates the chemical scheme generation after generation. The maximum number of generations can be controlled, and can be used to develop chemical schemes that include a growing number of species generations. Figure 2a, e shows the simulated mass distribution when the scheme includes one generation only. In this case, first generation organic species are effectively treated as non reactive compounds that may partition between the various phases. The parent hydrocarbon examined is hexadecane and the simulation is performed with $C_{\mathrm{OA}}$ set to $10 \mu \mathrm{g} \mathrm{m}^{-3}$. First generation products are $\mathrm{C}_{16}$ species and include 1-4 hydroxy-ketones (49\% on a carbon basis), monofunctional nitrates $(28 \%), 1-4$ hydroxy-nitrates $(21 \%)$, and trifunctional species (2\%), mostly 1-4-7 dihydroxyketone. The carbon atoms of these first generation species partition to the gas and aerosol phases in a ratio of about $4: 1$. Figure 2 i gives the simulated volatility distribution of the species after 5 days of 
atmospheric oxidation. For the conditions of the simulation, a species is equally split between the two phases when its saturation vapor pressure is $10^{-9} \mathrm{~atm}(\xi=0.5$, see Eq. 2$)$. A species can be considered as semi volatile when $\xi$ is in the 0.01-0.99 range. This corresponds here to saturation vapor pressure in the $10^{-11}-10^{-7}$ atm range. Most first generation products have volatilities in that range and thus behave as semi-volatile compounds (see Fig. 2i). Including a chemical loss to produce the set of second generation species therefore removes not only the gas phase species but also those absorbed in the aerosol phase due to re-volatilisation of firstgeneration products to maintain the thermodynamic equilibrium between the particle and gas phases. After gas phase processing, a fraction of the next generation species return to the particle phase with an increased oxidation state. This mechanism has been named "semi-volatile pumping" (Miracolo et al., 2010). This behavior is seen in Fig. 2b, $\mathrm{f}$ when the chemical scheme is generated up to the second generation species. The carbon distribution between the two phases is about 50/50 after a few days of atmospheric oxidation. The contribution of first generation species to the aerosol mass budget does not then exceed a few percent (see Fig. 2b, f). The volatility distribution of the second generation species spans 14 orders of magnitude. The functionalization of the carbon backbone leads to species that can here be considered as non-volatile when $P^{\text {vap }}$ is below $10^{-11}$ atm (i.e. $\xi>0.99$ ). For these species, the gas phase concentration is negligible and oxidation becomes a minor process. The fragmentation route leads to volatile species $\left(P^{\text {vap }}>10^{-7} \mathrm{~atm}\right)$ with a lower number of carbon atoms. The fraction of the second generation species in the semi-volatile and volatile category will be subject to oxidation if the mechanism is extended to higher generations as seen in Fig. 2d, h.

This progressive evolution lasts as long as oxidation produces organic species with high enough volatilities to be further oxidized in the gas phase at a rate relevant in the context of atmospheric chemistry. The atmospheric lifetime of submicron aerosols does not exceed a few weeks. The "re-volatilization - gas phase oxidation" mechanism described above is therefore efficient if it occurs with a characteristic time lower than this aerosol lifetime. After 5 days of atmospheric processing, the mean (concentration weighted) $\mathrm{OH}$ rate constant of the aerosol contributors is $3 \times 10^{-11} \mathrm{~cm}^{3} \mathrm{~s}^{-1}$. For a typical $\mathrm{OH}$ concentration of $10^{6}$ molecule $\mathrm{cm}^{-3}$, a chemical lifetime of about one year may be estimated for $\xi=0.999$ (i.e. $C^{*}=10^{-3} C_{\mathrm{OA}}$ ). With this model configuration organic matter is thus either progressively transferred to the particle phase in a form that can be considered as a "permanent" non-volatile state or is finally oxidized to $\mathrm{CO}_{2}$. For hexadecane and the conditions of the simulation, Fig. 2 shows that about 6 oxidation steps must be taken into account to reach this state. Species contributing to SOA production are mostly products from the 2 nd to the 4 th generation. Species produced after at least 4 oxidation steps
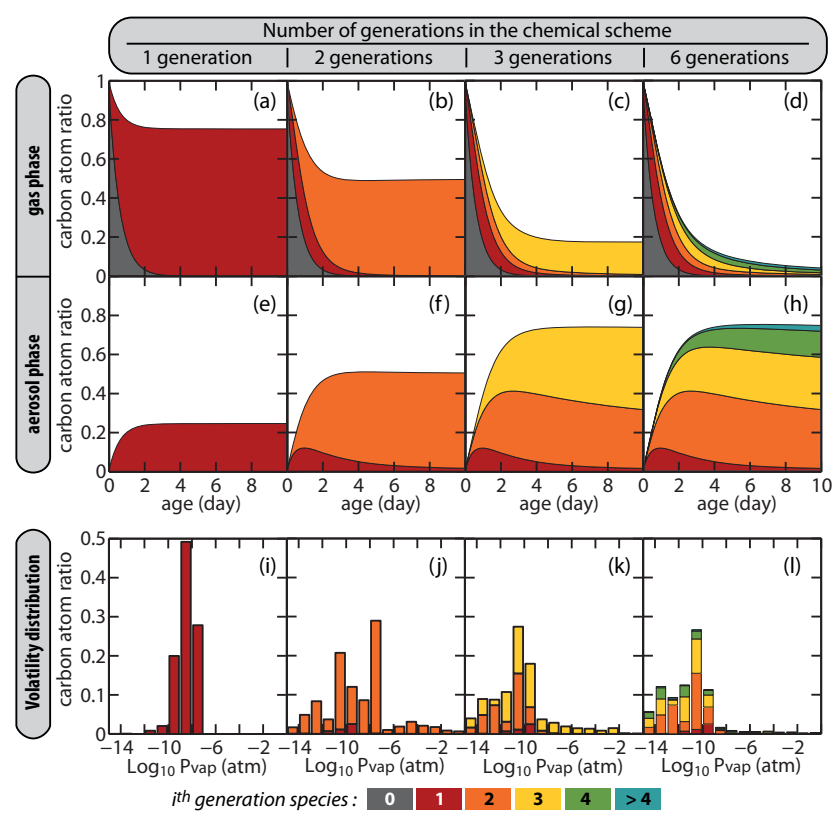

Fig. 2. Partitioning of organic carbon during hexadecane oxidation in the gas phase (1st row) and the aerosol phase (2nd row) and volatility distribution of the species (3rd row) given on logarithmically spaced bins. The number of successive generations taken into account in the gas-phase mechanism varies from 1 ( 1 st column) to 6 (4th column). Colors identify the contribution of the species from a given generation to the total carbon budget.

become non-negligible in the mass budget only after the second day of atmospheric oxidation.

\subsection{Number of generations and organic aerosol load}

For a given species, the partition ratio $\xi$ is a function of $C_{\mathrm{OA}}$ (see Eq. 2). The behavior of a given volatile species may change to semi-volatile or non-volatile if $C_{\mathrm{OA}}$ increases. The number of oxidation steps required to saturate the gas phase must therefore grow when $C_{\mathrm{OA}}$ decreases. Figure 3 shows the carbon distribution for the hexadecane simulation with $C_{\mathrm{OA}}$ set to $0.1,10$ and $1000 \mu \mathrm{g} \mathrm{m}^{-3}$. As expected, species produced after many generations contribute more significantly to SOA mass when $C_{\mathrm{OA}}$ decreases. For $C_{\mathrm{OA}}=$

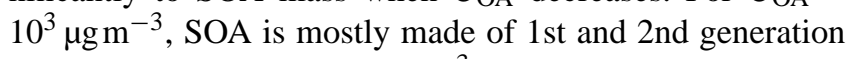
products. For $C_{\mathrm{OA}}=0.1 \mu \mathrm{g} \mathrm{m}^{-3}$, first generation products are negligible in the SOA mass budget even during the first day of atmospheric oxidation. For such low organic aerosol content, species produced after 4 or more generations contribute strongly to the SOA budget (up to $50 \%$, see Fig. 3d). The rate of SOA production therefore decreases with $C_{\mathrm{OA}}$ since longer timescale are required to produce substantial quantities of the higher generation products. For example, for $C_{\mathrm{OA}}=10^{3} \mathrm{\mu g} \mathrm{m}^{-3}$, the initial rate of transfer of carbon atoms from the precursor (here hexadecane) to the SOA contributors is $73 \%$ per day (see Fig. 3c). This rate drops to 40 


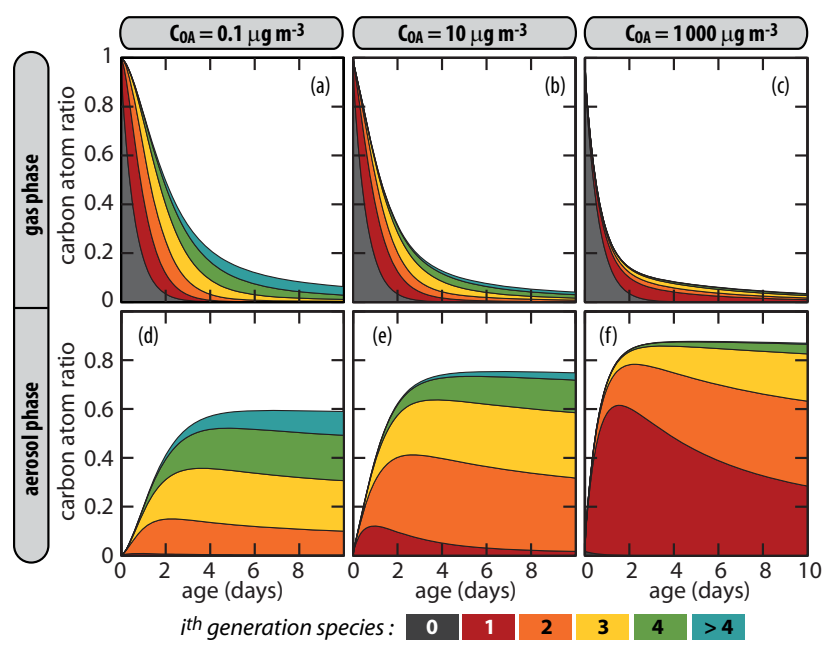

Fig. 3. Partitioning of organic carbon during hexadecane oxidation in the gas and aerosol phases as a function of $C_{\mathrm{OA}}$. Colors identify the contribution of the species from a given generation to the total carbon budget.

and $20 \%$ per day for $C_{\mathrm{OA}}$ values of 10 and $0.1 \mathrm{\mu g} \mathrm{m}^{-3}$, respectively.

\subsection{Precursor chain length and number of generations}

Increasing the number of carbon atoms of the precursor shifts toward lower values the vapor pressure of the species involved in a given oxidative reaction sequence. The number of oxidation steps needed to saturate the gas phase is thus expected to be smaller when the size of the carbon backbone increases. Figure 4 shows the organic carbon budget for octane, hexadecane, and tetracosane discriminated on a generational basis. Simulations are conducted with $C_{\mathrm{OA}}$ set to $10 \mu \mathrm{g} \mathrm{m}^{-3}$. For tetracosane, the first generation products are almost exclusively in the particle phase and represent about $80 \%$ of the carbon budget. The rate of chemical pumping is low, owing to the strong partitioning of the first generation species to the particle phase. However, a small fraction still remains in the gas phase at equilibrium. This fraction is subjected to oxidation and produces low volatility second generation products (about $15 \%$, see Fig. 4c). For octane, the successive generations of species produced during oxidation remain too volatile to condense with high yield in the particle phase owing to significant fragmentation of the carbon skeleton when the $\mathrm{O} / \mathrm{C}$ ratio becomes large (see Sect. 3.6). SOA contributors are $3 \mathrm{rd}$ and 4 th generation species produced after few days of atmospheric oxidation (less than $5 \%$ of the carbon budget). As expected, Fig. 4 shows that SOA contributors are produced on average with a growing number of oxidation steps (i.e. made of more oxidized organic species) when the carbon backbone of the parent compound decreases in length. Oxidation states of SOA contributors are examined in more detail in Sect. 3.6.

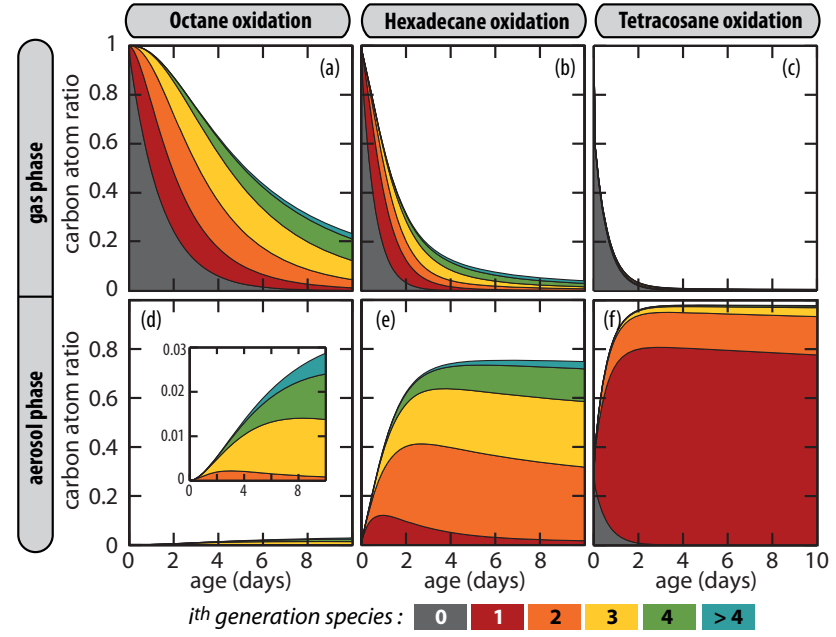

Fig. 4. Partitioning of organic carbon during octane, hexadecane and tetracosane oxidation in the gas and aerosol phases. Colors identify the contribution of the species from a given generation to the total carbon budget. The inset in (d) shows the carbon atom ratio with an expanded scale.

\subsection{SOA yield and organic aerosol load}

Figure 5 shows the maximum carbon atom ratio in the particle phase as a function of $C_{\mathrm{OA}}$ for $\mathrm{C}_{8}$ to $\mathrm{C}_{20} n$-alkanes. This maximum ratio is observed after the consumption of the parent hydrocarbon (see Fig. 1). The maximum ratio is therefore equivalent to a SOA yield $Y_{\mathrm{C}}$ expressed on a carbon basis. As expected, $Y_{\mathrm{C}}$ grows with the chain length and with $C_{\mathrm{OA}}$. For $\mathrm{C}_{8}-\mathrm{C}_{14}$ alkanes, $Y_{\mathrm{C}}$ increases by about $10 \%$ for each carbon atom added to backbone. This increase then levels off for longer chain length when $Y_{\mathrm{C}}$ approaches unity (see Fig. 5). $Y_{\mathrm{C}}$ also shows a logarithmic growth with $C_{\mathrm{OA}}$ in the $10^{-1}-10^{3} \mu \mathrm{g} \mathrm{m}^{-3}$ range. For the $\mathrm{C}_{10}$ to $\mathrm{C}_{16}$ series, the $Y_{C}$ increase is in the range of $7-10 \%$ per decade in $C_{\mathrm{OA}}$. The slope is slightly lower for longer carbon chains, as $Y_{\mathrm{C}}$ approaches unity. Figure 5 shows significant yields at low $C_{\mathrm{OA}}$ concentration even for comparatively small carbon backbones. For example, for $C_{\mathrm{OA}}=0.1 \mu \mathrm{g} \mathrm{m}^{-3}, Y_{\mathrm{C}}$ is $7 \%$ for decane and $41 \%$ for tetradecane. However, the timescale to reach the maximum yield increases as $C_{\mathrm{OA}}$ or hydrocarbon carbon chain length decrease (see Sect. 3.3). For example, the atmospheric oxidation timescale required to reach the maximum yield is about 4 days for tetradecane and exceeds 1 week for decane. These results suggest that a substantial fraction of the $\mathrm{C}_{10}-\mathrm{C}_{14}$ anthropogenic hydrocarbons may end up as organic aerosols given enough time for oxidation, even under substantial atmospheric dilution (i.e. low $\left.C_{\mathrm{OA}}\right)$. Confirming such yields on an experimental basis is a real challenge, owing to detection limits for such low $C_{\mathrm{OA}}$ conditions (below $1 \mathrm{\mu g} \mathrm{m}^{-3}$ ) and the timescale linked to this gas phase aging process. Furthermore, it should be pointed 


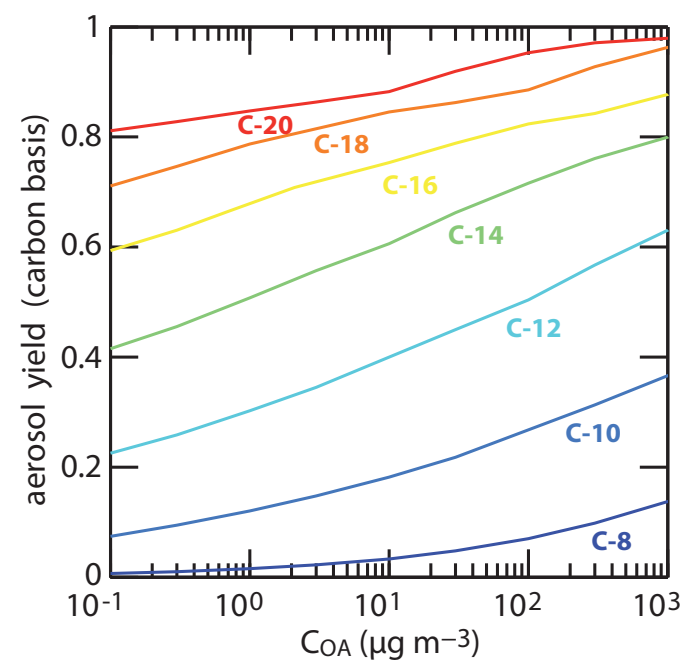

Fig. 5. Maximum carbon based aerosol yields simulated for the $n$ alkane series as a function of $C_{\mathrm{OA}}$.

out that most organic intermediates involved in the production of the low volatility SOA contributors are expected to be water soluble and may either be removed through dry and wet deposition or processed in cloud droplets.

\subsection{Trajectories in the $\overline{\mathrm{OS}}_{\mathrm{C}}$ - volatility space}

Various conceptual frameworks have been proposed to examine the oxidation trajectories from the parent organic species down to the ultimate oxidation product $\mathrm{CO}_{2}$. These frameworks are 2-dimensional spaces designed to capture both volatility and polarity changes during oxidation. For example, two-dimensional frameworks proposed for the design of models include polarity vs. carbon number (Pankow and Barsanti, 2009; Barsanti et al., 2011), mean carbon oxidation state $\left(\overline{\mathrm{OS}}_{\mathrm{C}}\right)$ vs. carbon number (Kroll et al., 2011), and $\overline{\mathrm{OS}}_{\mathrm{C}}$ (or O/C) vs. volatility (2-D-VBS, Donahue et al., 2011, 2012). Note that the degree of oxidation is a key parameter not only to examine SOA formation and aging but also to retrieve aerosol properties like hygroscopicity (e.g. Jimenez et al., 2009). Two metrics that can be measured during laboratory or field experiments have been proposed for the development of empirical models: the $\mathrm{O} / \mathrm{C}$ atom ratio (or $\overline{\mathrm{OS}}_{\mathrm{C}}$ ) and the volatility (Donahue et al., 2012). In this section, we examine the simulated trajectories for the $n$-alkane in the $\overline{\mathrm{OS}}_{\mathrm{C}}-C^{*}$ space described by Donahue et al. (2012).

The saturation vapor pressure $P^{\text {vap }}$ is a fundamental property estimated for each non-radical organic species by GECKO-A. Effective saturation mass concentrations $C^{*}$ are computed based on Eq. (2), assuming ideality and $\bar{M}_{\mathrm{OA}}=$ $250 \mathrm{~g} \mathrm{~mol}^{-1}$. Conversion of $P^{\mathrm{vap}}$ to $C^{*}$ is straightforward (e.g. $C^{*}=1.0 \mu \mathrm{g} \mathrm{m}^{-3}$ is equivalent to $P^{\mathrm{vap}}=10^{-10} \mathrm{~atm}$ ). GECKO-A provides the explicit oxidation schemes (see Sect. 2) and the mean carbon oxidation state can therefore be computed for each intermediate. The evolution of the species in $\overline{\mathrm{OS}}_{\mathrm{C}}-C^{*}$ space is given in Fig. 6, where the oxidation of octane, hexadecane and tetracosane is examined for $C_{\mathrm{OA}}$ of $10 \mu \mathrm{g} \mathrm{m}^{-3}$. Distributions are given for increasing atmospheric aging times, from 0 to 5 days. Position isomers having identical $C^{*}$ and $\overline{\mathrm{OS}}_{\mathrm{C}}$ are lumped into the same bubble in Fig 6. Overlaps in $C^{*}$ arise when the structure/activity relationship used to estimate $P^{\text {vap }}$ provides identical values for distinct position isomers. For clarity, species with a carbon atom ratio lower than $10^{-4}$ are also not considered in the distributions shown in Fig. 6.

In Fig. 6, species having the number of carbon atom of the parent compound (gray bubbles) are distinguished from species with smaller carbon skeletons (red bubbles). The former delineate the functionalization trajectories only (i.e. increasing number of functional groups on the carbon skeleton) while the latter draw joint fragmentation/functionalization trajectories (i.e. bond breaking of the carbon skeleton with an overall increased carbon oxidation state). As expected, Fig. 6 shows that fragmentation increases with chemical age and with shorter parent compound chain lengths (see also the $\mathrm{CO}$ and $\mathrm{CO}_{2}$ budget in Fig. 1). For octane, functionalization routes first lead to species with large $\overline{\mathrm{OS}}_{\mathrm{C}}$ after a few oxidation steps. As already stated, fragmentation probability increases with $\overline{\mathrm{OS}}_{\mathrm{C}}$ (see Sect. 3.1). Fragmentation occurs before the functionalization routes can produce large amount of low volatility species, ultimately leading to $\mathrm{CO}_{2}$ (see Fig. 1b). Therefore, SOA yield remains low even after 5 days of atmospheric oxidation. Tetracosane shows the opposite behavior. $C^{*}$ values for first generation products lie well below $C_{\mathrm{OA}}$ (see Fig. 6). The gas-phase chemical pump is therefore inefficient and $\overline{\mathrm{OS}}_{\mathrm{C}}$ remains below -1.5 for most SOA contributors Fragmentation is thus a negligible route in the tetracosane evolution. For hexadecane, there is significant fragmentation of the carbon skeleton, leading to a myriad of gas-phase products (see Fig. 6). Most fragmentation products evolve toward the production of $\mathrm{CO}$ and $\mathrm{CO}_{2}$ (upper right direction of Fig. 6). After 5 days of atmospheric processing, $16 \%$ of the hexadecane carbon atoms have been converted to $\mathrm{CO}$ or $\mathrm{CO}_{2}$ (see Fig. 1e). In the particle phase, species with 16 carbon atoms (i.e. derivatives of the parent compound) contribute to $92 \%$ of the SOA carbon budget. The mean number of carbon per species contributing to the SOA mass is 15.4 . The major SOA contributors are therefore produced via the functionalization pathways with only minor contributions from trajectories including at least one fragmentation step. The overall SOA oxidation state remains low, most species having an $\overline{\mathrm{OS}}_{\mathrm{C}}$ between -1.0 and -2.0 (see Fig. 6k).

\subsection{Highly oxygenated aerosols (OOA) vs. hydrocarbon like organic aerosols (HOA)}

Atmospheric observations based on aerosol mass spectrometer (AMS) measurements show that submicron organic 


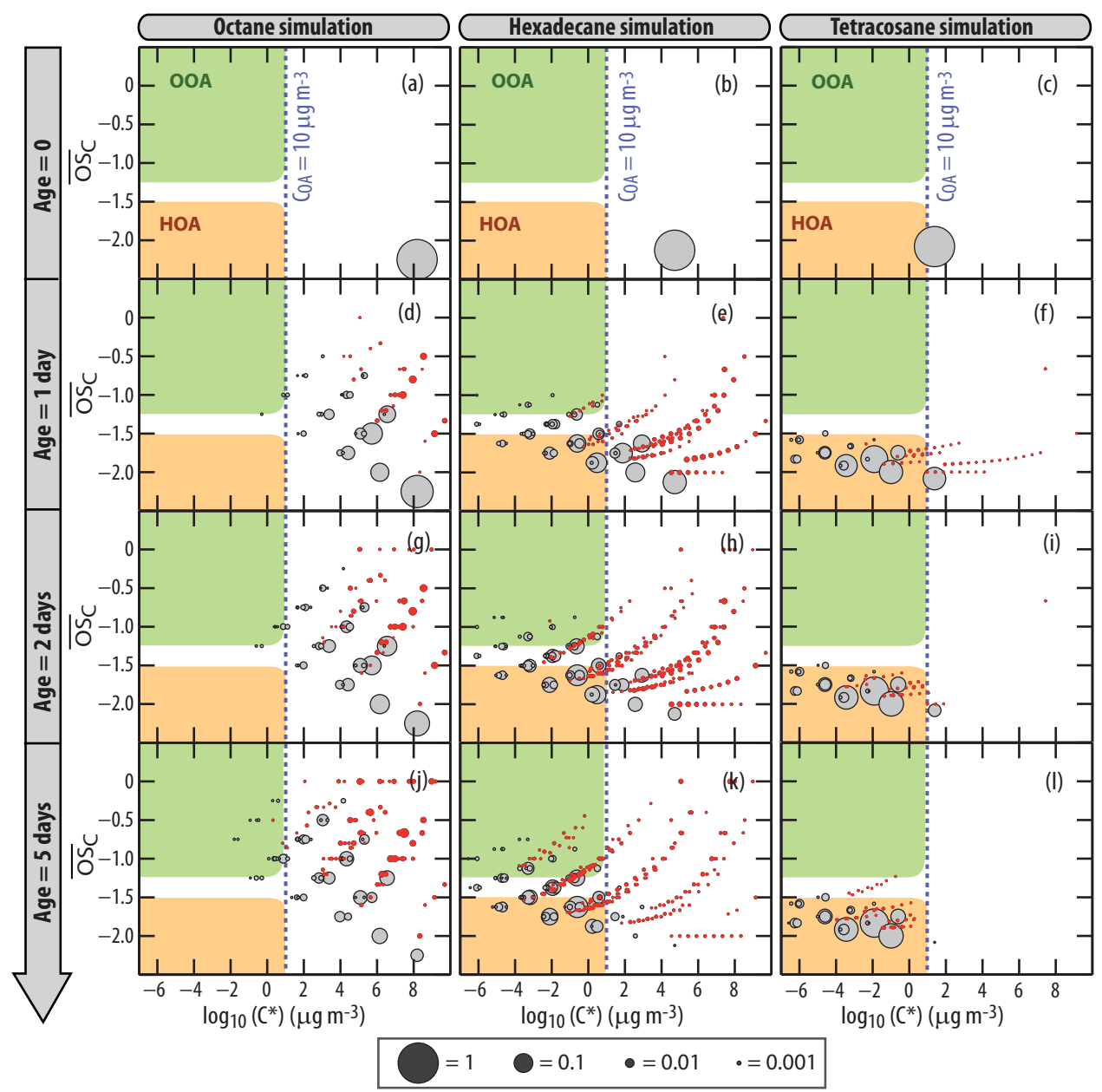

Fig. 6. Volatility and mean carbon oxidation state of the species produced during the oxidation of octane (1st column), hexadecane ( 2 nd column) and tetracosane (3rd column) as a function of aging time. Contribution of a species to the carbon budget is proportional to the volume of the bubble. Position isomers having identical volatility and oxidation state are lumped into the same bubble. Grey bubbles denote species having the carbon skeleton of the parent hydrocarbon. Red bubbles denote species with less carbon atoms than the parent compound. The blue dotted lines indicate the organic aerosol concentration $C_{\mathrm{OA}}$ prescribed for the simulation.

aerosols can be categorized into a few components or factors (e.g. Zhang et al., 2005). One of these components consists of highly oxygenated organic aerosols (OOA) (Zhang et al., 2005,2007 ) and is characterized by an $\mathrm{O} / \mathrm{C}$ ratio larger than 0.25 (Jimenez et al., 2009). This OOA component is usually given equivalent status to SOA. $\overline{\mathrm{OS}}_{\mathrm{C}}$ can be approximated based on the elemental $\mathrm{O} / \mathrm{C}$ and $\mathrm{H} / \mathrm{C}$ ratios (Kroll et al., 2011). Analysis of elemental ratios measured for organic aerosols shows that $\mathrm{O} / \mathrm{C}$ ratio is on average a linear function of $\mathrm{H} / \mathrm{C}$ ratio (Heald et al., 2010). The combination of these relationships leads to an average $\overline{\mathrm{OS}}_{\mathrm{C}} \approx 3(\mathrm{O} / \mathrm{C})-2$ (Donahue et al., 2012). OOA can therefore be equivalently characterized by an $\overline{\mathrm{OS}}_{\mathrm{C}}$ greater than about -1.25 . Another often-reported component shows features resembling emissions from motor exhausts and is usually named hydrocarbon like organic aerosols (HOA) (e.g. Zhang et al., 2005). This component is commonly ascribed to primary organic aerosols (POA). The expected $\overline{\mathrm{OS}}_{\mathrm{C}}$ for this $\mathrm{HOA}$ factor is below -1.5 (Donahue et al., 2012).

The shaded green area in Fig. 6 marks the OOA domain. The tetracosane oxidation simulation yields negligible amounts of species falling in that domain. For octane, the simulated SOA contributors match the oxidation state expected for OOA but, as discussed above, the aerosol yield is very low (see Fig. 1b). The hexadecane oxidation simulation yields SOA contributors that are mostly too reduced to be categorized as OOA (see Fig. 6). The OOA fraction grows slowly with age but remains a minor component. After 5 days of atmospheric processing, OOA contributes only $10 \%$ of the overall SOA production on a carbon atom basis in the hexadecane case. The shaded orange area in Fig. 6 marks the HOA domain. Interestingly, most simulated SOA contributors during hexadecane and tetracosane oxidation fall in the HOA domain. After 5 days of atmospheric processing, 
species in the HOA domain contribute $61 \%$ of the overall SOA production in the hexadecane case. Virtually all SOA contributors fall in the HOA category in the tetracosane simulation (see Fig. 6).

Species produced during octane and hexadecane oxidation border the right and bottom of the OOA domain, respectively, suggesting that $n$-alkanes of intermediate carbon chain length (i.e. $\mathrm{C}_{9}-\mathrm{C}_{15}$ ) might produce OOA with greater yields. Figure 7 shows the simulated species distribution after 5 days of atmospheric oxidation for decane, dodecane and tetradecane. As expected, the fraction of SOA contributors falling in the OOA category decreases with increasing carbon chain length. On a carbon atom basis, OOA represents $82 \%, 49 \%$, $22 \%$ of SOA produced after 5 days of atmospheric oxidation of decane, dodecane and tetradecane, respectively. The SOA yield and the OOA fraction show opposite trends, increasing and decreasing, respectively with the chain length. For an aging time of 5 days and for $C_{\mathrm{OA}}=10 \mu \mathrm{g} \mathrm{m}^{-3}$, the OOA carbon yield $Y_{\mathrm{C}}^{\mathrm{OOA}}$ (i.e. OOA produced per parent hydrocarbon reacted) is greatest for the dodecane oxidation, reaching 0.19 . Note that the fraction of SOA contributors falling in the HOA domain grows with the chain length (see Fig. 7). For an aging period of 5 days, HOA represents $8 \%, 24 \%$ and $35 \%$ of SOA produced in the simulation of decane, dodecane and tetradecane, respectively.

Figure 8 shows $Y_{\mathrm{C}}^{\mathrm{OOA}}$ computed for $\mathrm{C}_{8}-\mathrm{C}_{18} n$-alkane as a function of $C_{\mathrm{OA}}$. For the condition explored within this study, $Y_{\mathrm{C}}^{\mathrm{OOA}}$ never exceeds $25 \%$. For any given precursor, $Y_{\mathrm{C}}^{\mathrm{OOA}}$ exhibits a bell shaped curve which arises from the competition between fragmentation and functionalization. The functionalization pathways dominate the initial oxidation steps. For high $C_{\mathrm{OA}}$ content, first generation species partition to the aerosol phase. The gas phase chemical pump efficiency decreases and the OOA fraction remains low, explaining the low $Y_{\mathrm{C}}^{\mathrm{OOA}}$ values even though $Y_{\mathrm{C}}$ is large. For low $C_{\mathrm{OA}}$ content, many successive oxidation steps are required to produce species with low enough volatility to condense. As stated above, fragmentation pathways dominate the gas phase oxidation of highly oxygenated species and most species then evolve toward $\mathrm{CO}_{2}$ production before partitioning to the aerosol phase. Both $Y_{\mathrm{C}}^{\mathrm{OAA}}$ and $Y_{\mathrm{C}}$ are therefore low. The maximum $Y_{\mathrm{C}}^{\mathrm{OOA}}$ is observed when $C_{\mathrm{OA}}$ is low enough to allow an efficient gas phase production of oxygenated species but high enough to allow condensation and avoid significant fragmentation of the carbon skeleton. This maximum yield shifts to lower $C_{\mathrm{OA}}$ values as the carbon chain length of the precursor increases (see Fig. 8).

Two subtypes of OOA can usually be distinguished based on factor analysis of AMS data, the first being attributed to highly oxidized low-volatile species (LV-OOA) the second being attributed to less oxidized semi-volatile species (SV-OOA) (Jimenez et al., 2009). Atmospheric observations suggest that SV-OOA is rather fresh OA which evolves to LV-OOA during photochemical processing (Jimenez et al.,
2009). The dotted contours in Fig. 7 delineate the LV-OOA and SV-OOA envelopes depicted by Jimenez et al. (2009) and Donahue et al. (2012). No species in our simulations fall in the LV-OOA domain and the OOA contributors lie in the lower range of SV-OOA oxidation state. The configuration of the model appears clearly unable to explain the production of LV-OOA from $n$-alkane parent compounds. This statement holds for carbon skeletons of any size and for any aging time relevant in the context of atmospheric oxidation.

Figures 6 and 7 show that most SOA contributors are too reduced to be categorized as OOA (i.e. with an $\overline{\mathrm{OS}}_{\mathrm{C}}$ greater than -1.25 ). Simulated OOA represents therefore only a fraction of the SOA produced during the oxidation of $n$-alkanes. The OOA contribution to the overall SOA budget decreases when the chain length of the parent compound increases, and appears to be a minor component for $\mathrm{C}_{>16} n$ alkanes. According to this model version, the OOA component may thus greatly underestimate SOA. On the other hand, most simulated SOA contributors are reduced enough to be categorized as HOA (i.e. with an $\overline{\mathrm{OS}}_{\mathrm{C}}$ lower than -1.5). Unlike OOA, the simulated HOA contribution to the SOA budget increases with the chain length of the parent compound, and appears as the major component for $\mathrm{C}_{>16} n$-alkanes. According to this model version, the HOA component may thus overestimate POA.

\section{Conclusions}

Explicit chemical mechanisms reflect the current knowledge of the transformations occurring in the atmosphere. Explicit schemes were generated for $\mathrm{C}_{8}-\mathrm{C}_{24} n$-alkanes using the GECKO-A tool. Simulations were conducted to explore SOA formation for various concentrations of preexisting aerosol. In the version of the model examined here, gas-aerosol equilibrium is assumed at each time step for each species and the aerosol phase is assumed to be an inert phase. As expected, simulation results show that (i) SOA yield increases with the carbon chain length of the parent hydrocarbon, (ii) SOA yield decreases with decreasing $C_{\mathrm{OA}}$, (iii) SOA production rates are faster with increasing $C_{\mathrm{OA}}$, and (iv) the number of oxidation steps (i.e. generations) needed to describe SOA formation and evolution grows when $C_{\mathrm{OA}}$ decreases. However, most simulated SOA contributors are found to be not oxidized enough to be categorized as OOA but reduced enough to be categorized as HOA. This trend increases with the carbon chain length of the parent $n$-alkane. This model version therefore suggests that OOA may underestimate SOA, while HOA may overestimate POA. The model was unable to produce highly oxygenated aerosols (OOA) with large yields. In particular, this model configuration did not lead to the production of species having carbon oxidation states and volatilities matching the LV-OOA subtype usually observed in situ for SOA, even after 10 days of atmospheric processing with low $C_{\mathrm{OA}}$ content. Oxidation of $n$-alkanes leads to species 


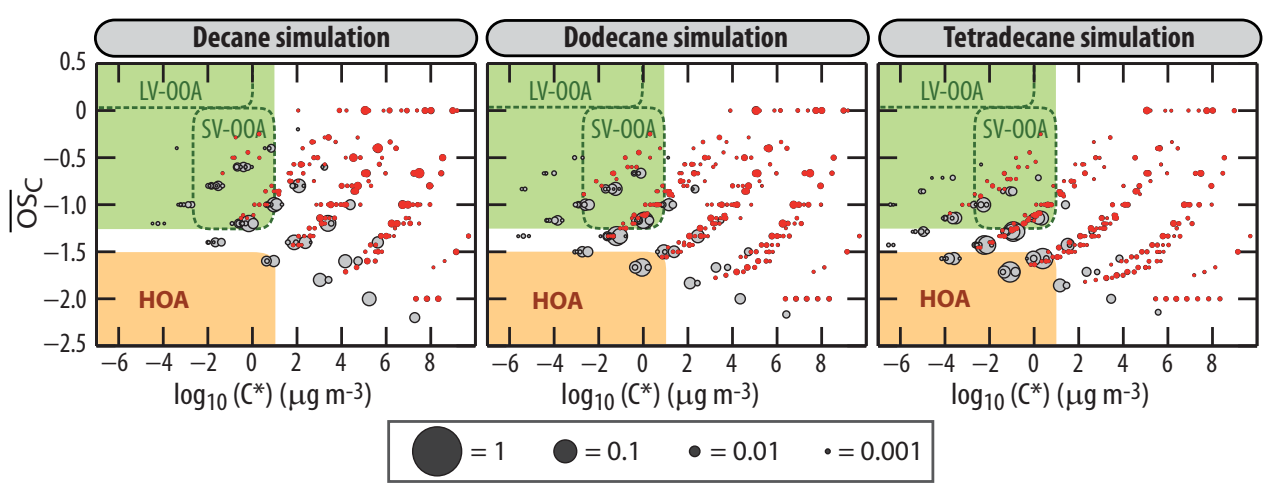

Fig. 7. Volatility and mean carbon oxidation state of the species produced during the oxidation of decane (1st column), dodecane (2nd column) and tetradecane (3rd column). Simulations are performed with $C_{\mathrm{OA}}=10 \mu \mathrm{g} \mathrm{m}^{-3}$ and the distributions are given for an aging time of 5 days. See caption of Fig. 6 for the color code of the bubbles.

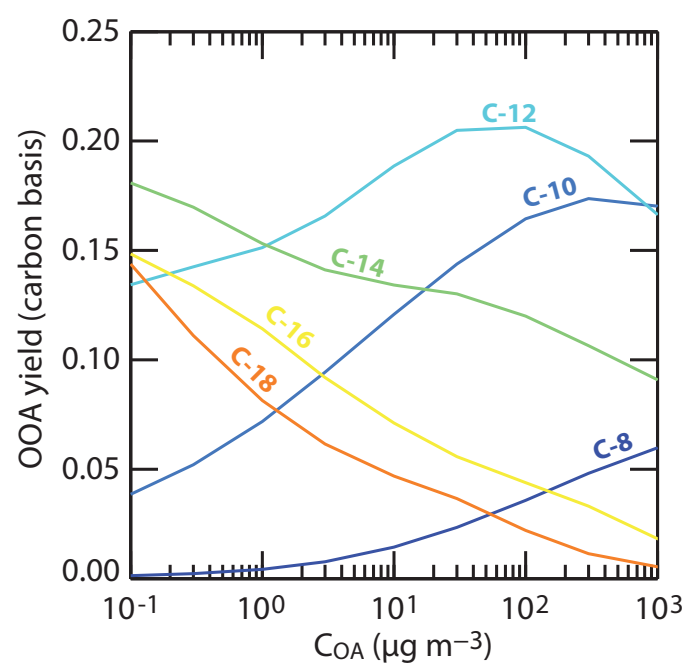

Fig. 8. Yield of highly oxygenated organic aerosol (OOA) for $\mathrm{C}_{8}-$ $\mathrm{C}_{18} n$-alkane as a function of $C_{\mathrm{OA}}$. Yields are computed for an aging time of 5 days.

having either too low volatility to activate the gas phase chemical pump efficiently (long carbon chain) or too high $\mathrm{O} / \mathrm{C}$ ratio to avoid fragmentation and $\mathrm{CO}_{2}$ production (short carbon chain). Similar behavior has been recently described by Cappa et al. (2012), based on a kinetic and statistical oxidation model.

Atmospheric observations show that the OOA component is ubiquitous and define a target for proposed mechanisms (Donahue et al., 2012). Various hypotheses can be raised to explain why the simulated oxidation of the $n$-alkanes does not overwhelmingly reach that target. The first possibility is that $n$-alkanes are not representative surrogates for the IVOC emitted in the atmosphere. These IVOC species constitute a complex mixture of linear, branched and cyclic alkanes, alkenes and aromatics (e.g. Fraser et al., 1997; Schauer et al.,
1999, 2002; El Haddad et al., 2009). Branched and unsaturated species may behave differently from the $n$-alkanes. For example, branched alkanes are more prone to fragment in the early stage of the oxidation (e.g. Atkinson, 2007; Atkinson et al., 2008), leading to lower SOA yield than their corresponding linear analogue (Lim and Ziemann, 2009) but likely with an enhanced mean carbon oxidation state. Similarly, alkenes yield to higher fragmentation than their corresponding saturated analogue (e.g. Atkinson and Arey, 2003) but also lead to the production of more oxidized multifunctional species (e.g. dihydroxycarbonyls) as first firstgeneration products (Matsunaga et al., 2009). It is also possible that the explicit schemes generated by GECKO-A are not representative of the gas phase oxidation processes actually occurring in the atmosphere. The protocol included in GECKO-A to design the oxidation mechanism (Aumont et al., 2005) is based on the current understanding of atmospheric organic chemistry. The chemistry of most oxygenated organic molecules investigated so far concerns rather small carbon chains (typically below $\mathrm{C}_{8}$ ) bearing 1 or 2 functional groups (e.g. Calvert et al., 2011). Empirical SARs based on this experimental data are extrapolated to infer the chemistry of species bearing many functional groups. This extrapolation may not be appropriate. For example, the functionalization vs. fragmentation pathways directly depend on (i) which reactive sites of the molecule react with the $\mathrm{OH}$ radical, and (ii) the evolution of the alkoxy radicals produced during the oxidation (e.g. Atkinson and Arey, 2003; Calvert et al., 2011). The rates of these 2 key reaction steps are strongly modified by neighboring functional groups (e.g. Kwok and Atkinson, 1995; Atkinson, 2007). Branching ratios may thus be erroneously computed with available SARs when applied to the multifunctional species produced beyond the first generation. Finally, the assumption made in this version of the model that the condensed phase is chemically inert is clearly crude. For example, a major category of first oxidation products, hydroxycarbonyls (see Sect. 3.2), were 
found to be converted into dihydrofurans by a heterogeneous process (e.g. Atkinson et al., 2008), a likely key transformation in the formation of SOA (Lim and Ziemann, 2009). Furthermore, oxidative reactions occurring in the aerosol phase have been observed for squalane, a branched $\mathrm{C}_{30}$ alkane, and may play a key role in the aging of organic aerosols (e.g. Kroll et al., 2009). For example, atmospheric observations show that carboxylic acid is a major functional group found in aerosols (Sempere and Kawamura, 1994; Decesari et al., 2000; Kanakidou et al., 2005) but this group does not contribute significantly to the carbon budget simulated with GECKO-A (Lee-Taylor et al., 2011). It is unlikely that a gas phase chemical source is efficient enough to account for the measured values (Aumont et al., 2000). The conjunction of $\mathrm{C}-\mathrm{C}$ bond breaking in the aerosol phase and the production of carboxylic acid at the terminal carbon atom of the fragment would lead to production of species falling in the LV-OOA subtype. Oxidation in the condensed phase is likely a key process to shift IVOC oxidative trajectories toward the production of organic aerosol with higher mean carbon oxidation states. Sensitivity studies will be performed to test the likelihood of these assumptions.

Acknowledgements. NCAR is sponsored by the National Science Foundation. JLT was supported and SM was supported in part by a grant from the US Department of Energy, Office of Science, BER, DE-FG02-ER65323. The support from the French ANR project MEGAPOLI - PARIS (ANR-09-BLAN-0356) is acknowledged. The study has been performed in the frame of the PRIMEQUAL programme of the French Ministry of Ecology, Energy, Sustainable Development and Sea.

Edited by: J. H. Seinfeld

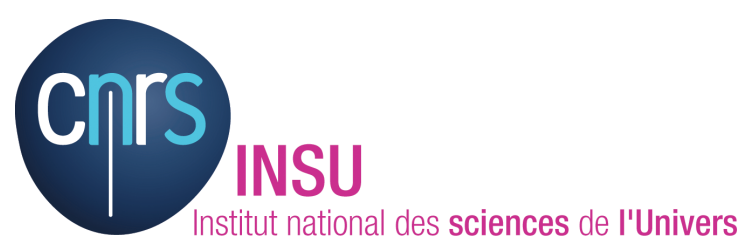

The publication of this article is financed by CNRS-INSU.

\section{References}

Atkinson, R.: Rate constants for the atmospheric reactions of alkoxy radicals: an updated estimation method, Atmos. Environ., 41, 8468-8485, doi:10.1016/j.atmosenv.2007.07.002, 2007.

Atkinson, R. and Arey, J.: Atmospheric degradation of volatile organic compounds, Chem. Rev., 103, 4605-4638, doi:10.1021/cr0206420, 2003.

Atkinson, R., Arey, J., and Aschmann, S. M.: Atmospheric chemistry of alkanes: review and recent developments, Atmos. Environ., 42, 5859-5871, doi:10.1016/j.atmosenv.2007.08.040, 2008.

Aumont, B., Madronich, S., Bey, I., and Tyndall, G. S.: Contribution of secondary VOC to the composition of aqueous atmospheric particles: a modeling approach, J. Atmos. Chem., 35, 59-75, doi:10.1023/a:1006243509840, 2000.

Aumont, B., Szopa, S., and Madronich, S.: Modelling the evolution of organic carbon during its gas-phase tropospheric oxidation: development of an explicit model based on a self generating approach, Atmos. Chem. Phys., 5, 2497-2517, doi:10.5194/acp-52497-2005, 2005.

Aumont, B., Camredon, M., Valorso, R., Lee-Taylor, J., and Madronich, S.: Development of systematic reduction techniques to describe the $\mathrm{SOA} / \mathrm{VOC} / \mathrm{NO}_{\mathrm{X}} / \mathrm{O}_{3}$ system, in: Atmospheric Chemical Mechanisms Conference, Air Quality Research Center, UC Davis, CA, 10-12 December 2008.

Barley, M. H. and McFiggans, G.: The critical assessment of vapour pressure estimation methods for use in modelling the formation of atmospheric organic aerosol, Atmos. Chem. Phys., 10, 749767, doi:10.5194/acp-10-749-2010, 2010.

Barsanti, K. C., Smith, J. N., and Pankow, J. F.: Application of the $\mathrm{np}$ plus $\mathrm{mP}$ modeling approach for simulating secondary organic particulate matter formation from alpha-pinene oxidation, Atmos. Environ., 45, 6812-6819, doi:10.1016/j.atmosenv.2011.01.038, 2011.

Bethel, H. L., Atkinson, R., and Arey, J.: Kinetics and products of the reactions of selected diols with the $\mathrm{OH}$ radical, Int. J. Chem. Kinet., 33, 310-316, 2001.

Calvert, J. G., Derwent, R. G., Orlando, J. J., Tyndall, G., and Wallington, T. J.: The mechanisms of atmospheric oxidation of the alkanes, Oxford University Press, New York, NY, 2008.

Calvert, J. G., Mellouki, A., Orlando, J. J., Pilling, M. J., and Wallington, T. J.: The mechanisms of atmospheric oxidation of the oxygenates, Oxford University Press, New York, NY, 2011.

Camredon, M., Aumont, B., Lee-Taylor, J., and Madronich, S.: The SOA/VOC/NO $\mathrm{N}_{\mathrm{x}}$ system: an explicit model of secondary organic aerosol formation, Atmos. Chem. Phys., 7, 5599-5610, doi:10.5194/acp-7-5599-2007, 2007.

Cappa, C. D. and Wilson, K. R.: Multi-generation gas-phase oxidation, equilibrium partitioning, and the formation and evolution of secondary organic aerosol, Atmos. Chem. Phys. Discuss., 12, 3295-3356, doi:10.5194/acpd-12-3295-2012, 2012.

Chacon-Madrid, H. J. and Donahue, N. M.: Fragmentation vs. functionalization: chemical aging and organic aerosol formation, Atmos. Chem. Phys., 11, 10553-10563, doi:10.5194/acp11-10553-2011, 2011.

Chan, A. W. H., Kautzman, K. E., Chhabra, P. S., Surratt, J. D., Chan, M. N., Crounse, J. D., Kürten, A., Wennberg, P. O., Flagan, R. C., and Seinfeld, J. H.: Secondary organic aerosol formation from photooxidation of naphthalene and alkylnaphthalenes: implications for oxidation of intermediate volatility organic compounds (IVOCs), Atmos. Chem. Phys., 9, 3049-3060, doi:10.5194/acp-9-3049-2009, 2009.

Compernolle, S., Ceulemans, K., and Müller, J.-F.: Technical Note: Vapor pressure estimation methods applied to secondary organic aerosol constituents from $\alpha$-pinene oxidation: an intercomparison study, Atmos. Chem. Phys., 10, 6271-6282, doi:10.5194/acp-10-6271-2010, 2010.

Decesari, S., Facchini, M. C., Fuzzi, S., and Tagliavini, E.: Characterization of water-soluble organic compounds in atmospheric aerosol: a new approach, J. Geophys. Res.-Atmos., 105, 14811489, doi:10.1029/1999jd900950, 2000. 
Donahue, N. M., Robinson, A. L., Stanier, C. O., and Pandis, S. N.: Coupled partitioning, dilution, and chemical aging of semivolatile organics, Environ. Sci. Technol., 40, 2635-2643, doi:10.1021/esO52297c, 2006.

Donahue, N. M., Epstein, S. A., Pandis, S. N., and Robinson, A. L.: A two-dimensional volatility basis set: 1 . organic-aerosol mixing thermodynamics, Atmos. Chem. Phys., 11, 3303-3318, doi:10.5194/acp-11-3303-2011, 2011.

Donahue, N. M., Kroll, J. H., Pandis, S. N., and Robinson, A. L.: A two-dimensional volatility basis set - Part 2: Diagnostics of organic-aerosol evolution, Atmos. Chem. Phys., 12, 615-634, doi:10.5194/acp-12-615-2012, 2012.

Dzepina, K., Cappa, C. D., Volkamer, R. M., Madronich, S., DeCarlo, P. F., Zaveri, R. A., and Jimenez, J. L.: Modeling the multiday evolution and aging of secondary organic aerosol during MILAGRO 2006, Environ. Sci. Technol., 45, 3496-3503, doi:10.1021/es103186f, 2011.

El Haddad, I., Marchand, N., Dron, J., Temime-Roussel, B., Quivet, E., Wortham, H., Jaffrezo, J. L., Baduel, C., Voisin, D., Besombes, J. L., and Gille, G.: Comprehensive primary particulate organic characterization of vehicular exhaust emissions in France, Atmos. Environ., 43, 6190-6198, doi:10.1016/j.atmosenv.2009.09.001, 2009.

Fraser, M. P., Cass, G. R., Simoneit, B. R. T., and Rasmussen, R. A.: Air quality model evaluation data for organics .4. C-2-C-36 nonaromatic hydrocarbons, Environ. Sci. Technol., 31, 2356-2367, doi:10.1021/es960980g, 1997.

Goldstein, A. H. and Galbally, I. E.: Known and unexplored organic constituents in the earth's atmosphere, Environ. Sci. Technol., 41, 1514-1521, 2007.

Grieshop, A. P., Logue, J. M., Donahue, N. M., and Robinson, A. L.: Laboratory investigation of photochemical oxidation of organic aerosol from wood fires 1: measurement and simulation of organic aerosol evolution, Atmos. Chem. Phys., 9, 1263-1277, doi:10.5194/acp-9-1263-2009, 2009.

Heald, C. L., Kroll, J. H., Jimenez, J. L., Docherty, K. S., DeCarlo, P. F., Aiken, A. C., Chen, Q., Martin, S. T., Farmer, D. K., and Artaxo, P.: A simplified description of the evolution of organic aerosol composition in the atmosphere, Geophys. Res. Lett., 37, L08803, doi:10.1029/2010g1042737, 2010.

Hodzic, A., Jimenez, J. L., Madronich, S., Canagaratna, M. R., DeCarlo, P. F., Kleinman, L., and Fast, J.: Modeling organic aerosols in a megacity: potential contribution of semi-volatile and intermediate volatility primary organic compounds to secondary organic aerosol formation, Atmos. Chem. Phys., 10, 5491-5514, doi:10.5194/acp-10-5491-2010, 2010.

Jathar, S. H., Farina, S. C., Robinson, A. L., and Adams, P. J.: The influence of semi-volatile and reactive primary emissions on the abundance and properties of global organic aerosol, Atmos. Chem. Phys., 11, 7727-7746, doi:10.5194/acp-11-77272011, 2011.

Jimenez, J. L., Canagaratna, M. R., Donahue, N. M., Prevot, A. S. H., Zhang, Q., Kroll, J. H., DeCarlo, P. F., Allan, J. D., Coe, H., Ng, N. L., Aiken, A. C., Docherty, K. S., Ulbrich, I. M., Grieshop, A. P., Robinson, A. L., Duplissy, J., Smith, J. D., Wilson, K. R., Lanz, V. A., Hueglin, C., Sun, Y. L., Tian, J., Laaksonen, A., Raatikainen, T., Rautiainen, J., Vaattovaara, P., Ehn, M., Kulmala, M., Tomlinson, J. M., Collins, D. R., Cubison, M. J., Dunlea, E. J., Huffman, J. A., Onasch, T. B., Alfarra, M. R.,
Williams, P. I., Bower, K., Kondo, Y., Schneider, J., Drewnick, F., Borrmann, S., Weimer, S., Demerjian, K., Salcedo, D., Cottrell, L., Griffin, R., Takami, A., Miyoshi, T., Hatakeyama, S., Shimono, A., Sun, J. Y., Zhang, Y. M., Dzepina, K., Kimmel, J. R., Sueper, D., Jayne, J. T., Herndon, S. C., Trimborn, A. M., Williams, L. R., Wood, E. C., Middlebrook, A. M., Kolb, C. E., Baltensperger, U., and Worsnop, D. R.: Evolution of organic aerosols in the atmosphere, Science, 326, 1525-1529, doi:10.1126/science.1180353, 2009.

Kanakidou, M., Seinfeld, J. H., Pandis, S. N., Barnes, I., Dentener, F. J., Facchini, M. C., Van Dingenen, R., Ervens, B., Nenes, A., Nielsen, C. J., Swietlicki, E., Putaud, J. P., Balkanski, Y., Fuzzi, S., Horth, J., Moortgat, G. K., Winterhalter, R., Myhre, C. E. L., Tsigaridis, K., Vignati, E., Stephanou, E. G., and Wilson, J.: Organic aerosol and global climate modelling: a review, Atmos. Chem. Phys., 5, 1053-1123, doi:10.5194/acp5-1053-2005, 2005.

Kroll, J. H. and Seinfeld, J. H.: Chemistry of secondary organic aerosol: formation and evolution of low-volatility organics in the atmosphere, Atmos. Environ., 42, 3593-3624, doi:10.1016/j.atmosenv.2008.01.003, 2008.

Kroll, J. H., Smith, J. D., Che, D. L., Kessler, S. H., Worsnop, D. R., and Wilson, K. R.: Measurement of fragmentation and functionalization pathways in the heterogeneous oxidation of oxidized organic aerosol, Phys. Chem. Chem. Phys., 11, 8005-8014, doi:10.1039/b905289e, 2009.

Kroll, J. H., Donahue, N. M., Jimenez, J. L., Kessler, S. H., Canagaratna, M. R., Wilson, K. R., Altieri, K. E., Mazzoleni, L.R., Wozniak, A. S., Bluhm, H., Mysak, E. R., Smith, J. D., Kolb, C. E., and Worsnop, D. R.: Carbon oxidation state as a metric for describing the chemistry of atmospheric organic aerosol, Nature Chem., 3, 133-139, doi:10.1038/nchem.948, 2011.

Kwok, E. S. C. and Atkinson, R.: Estimation of hydroxyl radical reaction-rate constants for gas-phase organic-compounds using a structure-reactivity relationship - an update, Atmos. Environ., 29, 1685-1695, doi:10.1016/1352-2310(95)00069-b, 1995.

Lee-Taylor, J., Madronich, S., Aumont, B., Baker, A., Camredon, M., Hodzic, A., Tyndall, G. S., Apel, E., and Zaveri, R. A.: Explicit modeling of organic chemistry and secondary organic aerosol partitioning for Mexico City and its outflow plume, Atmos. Chem. Phys., 11, 13219-13241, doi:10.5194/acp-1113219-2011, 2011.

Li, G., Zavala, M., Lei, W., Tsimpidi, A. P., Karydis, V. A., Pandis, S. N., Canagaratna, M. R., and Molina, L. T.: Simulations of organic aerosol concentrations in Mexico City using the WRFCHEM model during the MCMA-2006/MILAGRO campaign, Atmos. Chem. Phys., 11, 3789-3809, doi:10.5194/acp-11-37892011, 2011.

Lim, Y. B. and Ziemann, P. J.: Products and mechanism of secondary organic aerosol formation from reactions of $n$-alkanes with $\mathrm{OH}$ radicals in the presence of $\mathrm{NO}_{\mathrm{x}}$, Environ. Sci. Technol., 39, 9229-9236, doi:10.1021/es051447g, 2005.

Lim, Y. B. and Ziemann, P. J.: Effects of molecular structure on aerosol yields from $\mathrm{OH}$ radical-initiated reactions of linear, branched, and cyclic alkanes in the presence of $\mathrm{NO}_{\mathrm{x}}$, Environ. Sci. Technol., 43, 2328-2334, doi:10.1021/es803389s, 2009.

Madronich, S. and Flocke, S.: Theoretical estimation of biologically effective UV radiation at the Earth's surfaceSolar, in: Solar Ultraviolet Radiation - Modeling, Measurements and Effects, edited 
by: Zerefos, C., Springer-Verlag, Berlin, 23-48, 1997.

Matsunaga, A., Docherty, K. S., Lim, Y. B., and Ziemann, P. J.: Composition and yields of secondary organic aerosol formed from $\mathrm{OH}$ radical-initiated reactions of linear alkenes in the presence of $\mathrm{NO}_{\mathrm{x}}$ : modeling and measurements, Atmos. Environ., 43, 1349-1357, doi:10.1016/j.atmosenv.2008.12.004, 2009.

Miracolo, M. A., Presto, A. A., Lambe, A. T., Hennigan, C. J., Donahue, N. M., Kroll, J. H., Worsnop, D. R., and Robinson, A. L.: Photo-oxidation of low-volatility organics found in motor vehicle emissions: production and chemical evolution of organic aerosol mass, Environ. Sci. Technol., 44, 1638-1643, doi:10.1021/es902635c, 2010.

Nannoolal, Y., Rarey, J., Ramjugernath, D., and Cordes, W.: Estimation of pure component properties: Part 1. Estimation of the normal boiling point of non-electrolyte organic compounds via group contributions and group interactions, Fluid Phase Equilibr., 226, 45-63, 2004.

Nannoolal, Y., Rarey, J., and Ramjugernath, D.: Estimation of pure component properties: Part 3. Estimation of the vapor pressure of non-electrolyte organic compounds via group contributions and group interactions, Fluid Phase Equilibr., 269, 117-133, 2008.

Pankow, J. F.: An absorption-model of the gas aerosol partitioning involved in the formation of secondary organic aerosol, Atmos. Environ., 28, 189-193, 1994.

Pankow, J. F. and Barsanti, K. C.: The carbon numberpolarity grid: a means to manage the complexity of the mix of organic compounds when modeling atmospheric organic particulate matter, Atmos. Environ., 43, 2829-2835, doi:10.1016/j.atmosenv.2008.12.050, 2009.

Presto, A. A., Miracolo, M. A., Donahue, N. M., and Robinson, A. L.: Secondary organic aerosol formation from high- $\mathrm{NO}_{\mathrm{x}}$ photo-oxidation of low volatility precursors: $n$-alkanes, Environ. Sci. Technol., 44, 2029-2034, doi:10.1021/es903712r, 2010.

Robinson, A. L., Donahue, N. M., Shrivastava, M. K., Weitkamp, E. A., Sage, A. M., Grieshop, A. P., Lane, T. E., Pierce, J. R., and Pandis, S. N.: Rethinking organic aerosols: semivolatile emissions and photochemical aging, Science, 315, 1259-1262, doi:10.1126/science.1133061, 2007.

Schauer, J. J., Kleeman, M. J., Cass, G. R., and Simoneit, B. R. T.: Measurement of emissions from air pollution sources. 2. C-1 through C-30 organic compounds from medium duty diesel trucks, Environ. Sci. Technol., 33, 1578-1587, doi:10.1021/es980081n, 1999.
Schauer, J. J., Kleeman, M. J., Cass, G. R., and Simoneit, B. R. T.: Measurement of emissions from air pollution sources. 5. C-1-C32 organic compounds from gasoline-powered motor vehicles, Environ. Sci. Technol., 36, 1169-1180, doi:10.1021/es0108077, 2002.

Sempere, R. and Kawamura, K.: Comparative distributions of dicarboxylic-acids and related polar compounds in snow rain and aerosols from urban atmosphere, Atmos. Environ., 28, 449-459, doi:10.1016/1352-2310(94)90123-6, 1994.

Tsimpidi, A. P., Karydis, V. A., Zavala, M., Lei, W., Molina, L., Ulbrich, I. M., Jimenez, J. L., and Pandis, S. N.: Evaluation of the volatility basis-set approach for the simulation of organic aerosol formation in the Mexico City metropolitan area, Atmos. Chem. Phys., 10, 525-546, doi:10.5194/acp-10-525-2010, 2010.

Valorso, R., Aumont, B., Camredon, M., Raventos-Duran, T., Mouchel-Vallon, C., Ng, N. L., Seinfeld, J. H., Lee-Taylor, J., and Madronich, S.: Explicit modelling of SOA formation from $\alpha$-pinene photooxidation: sensitivity to vapour pressure estimation, Atmos. Chem. Phys., 11, 6895-6910, doi:10.5194/acp-116895-2011, 2011.

Verwer, J. G. and Vanloon, M.: An evaluation of explicit pseudosteady-state approximation schemes for stiff ODE systems from chemical-kinetics, J. Comput. Phys., 113, 347-352, 1994.

Verwer, J. G., Blom, J. G., VanLoon, M., and Spee, E. J.: A comparison of stiff ODE solvers for atmospheric chemistry problems, Atmos. Environ., 30, 49-58, 1996.

Zhang, Q., Worsnop, D. R., Canagaratna, M. R., and Jimenez, J. L.: Hydrocarbon-like and oxygenated organic aerosols in Pittsburgh: insights into sources and processes of organic aerosols, Atmos. Chem. Phys., 5, 3289-3311, doi:10.5194/acp-5-3289-2005, 2005.

Zhang, Q., Jimenez, J. L., Canagaratna, M. R., Allan, J. D., Coe, H., Ulbrich, I., Alfarra, M. R., Takami, A., Middlebrook, A. M., Sun, Y. L., Dzepina, K., Dunlea, E., Docherty, K., DeCarlo, P. F., Salcedo, D., Onasch, T., Jayne, J. T., Miyoshi, T., Shimono, A., Hatakeyama, S., Takegawa, N., Kondo, Y., Schneider, J., Drewnick, F., Borrmann, S., Weimer, S., Demerjian, K., Williams, P., Bower, K., Bahreini, R., Cottrell, L., Griffin, R. J., Rautiainen, J., Sun, J. Y., Zhang, Y. M., and Worsnop, D. R.: Ubiquity and dominance of oxygenated species in organic aerosols in anthropogenically-influenced Northern Hemisphere midlatitudes, Geophys. Res. Lett., 34, L13801, doi:10.1029/2007g1029979, 2007. 